\title{
Endovascular thrombectomy for the treatment of acute ischemic stroke
}

\author{
Tratamento endovascular do acidente vascular isquêmico agudo
}

Cleusa P. Ferri', Anna Buehler', Uri Adrian Prync Flato', Paulo Puglia Junior², Jefferson G. Fernandes ${ }^{1}$

\begin{abstract}
Few patients benefit from the current standard treatment for acute ischemic stroke (AIS), encouraging the development of new treatments. Objective: To systematically review the literature on the efficacy and/or safety of endovascular thrombectomy in AIS compared to standard treatment and to identify ongoing randomized controlled trials (RCTs). Method: Searches for RCTs were performed in Medline/Embase, and for ongoing trials: International Clinical Trial Registry Platform, Clinicaltrials.gov and ISRCTN registry (to June 15th, 2015). Results: From the eight published RCTs, five showed the superiority of treatment that includes thrombectomy compared to standard care alone. From the 13 ongoing RCTs, 3 have been halted, one has not started, one has unknown status and eight will end between 2016 - 2020. Conclusion: Evidence favours a combination of the standard therapy with endovascular thrombectomy. The selection criteria however limit the number of people who can benefit. Further studies are needed to prove its cost-effectiveness.
\end{abstract}

Keywords: stroke, thrombectomy, systematic review, randomized controlled trial.

\section{RESUMO}

Poucos pacientes se beneficiam do atual tratamento para o acidente vascular cerebral isquêmico agudo (AVCIA), incentivando o desenvolvimento de novos tratamentos. Objetivo: Revisão sistemática da literatura sobre a eficácia e/ou segurança da trombectomia endovascular (TE) em AVCIA comparado com tratamento padrão (TP) e identificar ensaios clínicos randomizados controlados (ECR) atualmente em andamento. Método: Buscas por ECRs foram conduzidas no Medline, Embase, International Clinical Trial Registry Platform, Clinicaltrials.gov e no ISRCTN registry (to June 15th, 2015). Resultados: Oito ECRs publicados foram identificados, dos quais cinco mostraram superioridade do tratamento com trombectomia comparado ao TP. Dos 13 ERCs registrados, 3 foram suspensos, um não iniciou, um tem status desconhecido e oito encerrarão recrutamento entre 2016 e 2020. Conclusão: A evidência favorece a combinação do TP com a TE em relação ao TP somente. Os critérios de inclusão limitam o número daqueles que poderiam se beneficiar. Mais estudos são necessários para demonstrar o custo-efetividade desta intervenção.

Palavras-chave: acidente vascular cerebral, trombectomia, revisão sistemática, ensaios clínicos randomizados controlados.

Stroke is one of the main causes of death worldwide ${ }^{1,2}$. In Latin American and Caribbean countries, stroke is the leading or second single cause of death ${ }^{1}$, including in Brazil where stroke together with ischemic heart disease are the main causes of death ${ }^{3}$. There are a high number of survivors, with 62 million people in the world estimated to have had a stroke ${ }^{4}$ and many of them survive with significant loss of function or disability ${ }^{5,6}$. The prevalence of stroke survivors in low and middle-income countries varies, especially between rural and urban areas. A recent study conducted in five Latin American countries showed that the prevalence of self-reported stroke in a population aged 65 and over varied from 6.2 to $8.4 \%$ in urban sites and from 2.7 to $6.5 \%$ in rural sites 5 . Another study conducted in Latin America showed a prevalence of $8.4 \%$ in an adult population in urban Brazil $7^{7}$. Ischemic stroke accounts for about $85 \%$ of all strokes 8 .

\section{Intravenous thrombolysis}

The use of intravenous recombinant tissue plasminogen activator (rt-PA) (intravenous thrombolysis) is the standard treatment for acute ischemic stroke (AIS), and has been shown to be an effective treatment for suitable patients9. Its use $(0.9 \mathrm{mg} / \mathrm{kg}$, maximum dose $90 \mathrm{mg})$ is recommended for patients who can be treated within 3 to 4.5 hours of onset of

${ }^{1}$ Hospital Alemão Oswaldo Cruz, Instituto de Educação e Ciências da Saúde, Sao Paulo SP, Brazil;

${ }^{2}$ Hospital Alemão Oswaldo Cruz, Centro de Intervenção Cardiovascular, Sao Paulo SP, Brazil.

Correspondence: Cleusa Ferri; Hospital Alemão Oswaldo Cruz, Instituto de Educação e Ciências da Saúde; Rua João Julião, 245 / $1{ }^{\circ}$ andar; $01323-903$ São Paulo SP, Brasil; E-mail: ferricleusa@gmail.com

Conflict of interest: There is no conflict of interest to declare.

Support: We would like to thank the Brazilian Ministry of Health who sponsored this work through PROADI-SUS, a program to support the development of the Brazilian National Health System (Sistema Único de Saúde - SUS) in a partnership with the Hospital Alemão Oswaldo Cruz.

Received 15 July 2015; Received in final form 29 August 2015; Accepted 21 September 2015. 
ischemic stroke. The benefit of this therapy is time dependent and treatment should be initiated as quickly as possible once the eligibility criteria recommended by current guidelines is followed ${ }^{9}$. Treatment with intravenous rtPA is associated with increased rates of intracranial hemorrhage and the best way for preventing bleeding complications is through careful selection of patients.

Despite this, only a small proportion of patients benefit from intravenous t-PA, mainly due to its short therapeutic window ( $\leq 4.5$ hours) and possible adverse effects ${ }^{10,11}$. Systemic and/or brain haemorrhage and the low efficacy on the lysis of complex and voluminous thrombus are important limitations of intravenous thrombolysis ${ }^{12}$. These limitations have encouraged the search for other therapies than can be used with more patients and increase the rates of revascularization for acute ischemic stroke.

\section{Mechanical thrombectomy}

Non pharmacological technologies have appeared for the treatment of acute ischemic stroke, such as devices for mechanical thrombectomy, a technique that attempts to remove as much of the clot as possible. MERCI retriever (Concentric Medical, Mountain View, California, EUA) was the first to be approved by the FDA in 2005, and is constituted by a set of catheters that allow the flow to be proximally blocked and the clot to be approached and captured with a guide wire with a "corkscrew" like tip. The next device to be approved was the PENUMBRA System (Penumbra, Alameda, California, USA) which is currently in use in many centers. It was designed to perform revascularization using a technique of aspiration followed, if necessary, by direct extraction of the thrombus if any remained. As technology advances it created catheter with large lumens able to aspirate even voluminous thrombus. More recently stent retriever devices, which encapsulate the thrombus, have been developed. This allows a fast restoration of the blood flow and increase the efficacy of thrombolytic substances. There are currently an increasing number of companies providing this technology: SOLITAIRE (ev3, Plymouth, Minnesota); TREVO (Concentric Medical); Aperio (Acandis) and Revive (Codman Endovascular, 2013). It is important that the clot removal be done under proximal flow arrest promoted by a balloon guided catheter. The more recent generation of aspiration catheter and stent retrievers perform faster and better than MERCI.

\section{Objective}

This study aims to review the existing evidence on the benefits of thrombectomy in terms of clinical efficacy and/or safety in the treatment of acute ischemic stroke, compared to the current standard treatment (i.e. intravenous thrombolysis within 4.5 hours of symptom onset) alone. It also aims to identify ongoing randomized controlled trials and their likely contribution in the near future.

\section{METHOD}

\section{Search methods}

We searched in the electronic databases MEDLINE and EMBASE (from 01/01/2005 to 15/06/2015) limited to randomized controlled trials. In addition, we also searched reference lists of relevant articles. We scanned for registered ongoing or recently ended trials in the International Clinical Trial Registry Platform (ICTRP, www.who.int/ictrp), Clinicaltrials.gov, and ISRCTN Registry (http://www.isrctn. com/ (up to 15/06//2015).

\section{Eligibility criteria}

Only randomized controlled trials published in English were included. All RCTs which included endovascular therapy (any technology for thrombectomy) compared to treatment only with intravenous t-PA were considered. The same criteria were used to identify ongoing RCTs.

\section{RESULTS}

Table 1 describes published RCTs comparing endovascular thrombectomy with other interventions for AIS. Table 2 summarizes their main findings. We also identified 13 registered RCTs which are described in Table 3.

\section{Published RCTs}

\section{Initial trials showed no benefit of thrombectomy}

Three RCTs ${ }^{12-14}$ were published in 2013 showing no benefit of endovascular thrombectomy compared to standard care. None of them showed any superiority of endovascular treatment regarding efficacy ( functional independence at 90 days) and safety (mortality and symptomatic intracerebral haemorrhage).

\section{IMS-III trial}

The International Management of Stroke Trial III (IMS-III $)^{12}$ randomly allocated eligible patients who had received intravenous t-PA within three hours after the onset of the AIS symptoms to receive either the intravenous t-PA only, or the t-PA with additional endovascular treatment. The initial plan was to include 900 participants from 58 sites in the USA, Canada, Australia and Europe (1 intravenous t-PA for every 2 endovascular treatments + intravenous t-PA). However, recruitment stopped early for futility in the interim analysis of 656 participants (434 for the endovascular treatment and 222 for the intravenous t-PA only group). The device MERCI retriever was exclusively used at the beginning of the trial as it was the only device approved by the FDA. Newer devices were included later on in the trial as they were approved by the responsible authorities in each country. 
The primary outcome defined in this study was a measure of functional independence at 90 days after the intervention using the Rankin scale. Despite the higher rate of revascularization in the endovascular group, the proportion of patients with symptomatic intra-cerebral haemorrhage (6.2\% vs. $5.9 \%$ ), functional independence $(40.8 \%$ vs. $38.7 \%)$ and mortality $(10.1 \%$ vs. $21.6 \%)$ at 30 days were similar between the two arms.

\section{SYNTHESIS trial}

The Local Versus Systemic Thrombolysis for Acute Ischemic Stroke (SYNTHESIS) ${ }^{13}$ was a clinical trial with 362 patients with acute ischemic stroke who were randomly allocated to receive endovascular thrombolysis or mechanic thrombectomy, or a combination of these two procedures. As in IMS III ${ }^{12}$, mechanical thrombectomy was also applied using different types of devices. The primary outcome was also assessed using the modified Rankin scale ${ }^{15}$. In this study, the participants who received the endovascular treatment had the procedure on average one hour after the pharmacological intervention. Despite this, there was no statistically significant difference between those receiving the endovascular procedure compared to IV rt-PA alone in respect of disability at 90 days after the intervention ( $30.4 \%$ vs. $34.8 \%$ ), intracranial haemorrhage at 7 days (6\% vs. $6 \%$ ) and mortality ( $8 \%$ vs. $6 \%$ ).

\section{MR RESCUE trial}

The Mechanical Retrieval and Recanalization of Stroke Clots Using Embolectomy trial (MR RESCUE) ${ }^{14}$ hypothesized that patients who are beyond the therapeutic window of 4.5 hours after the onset of symptoms and have a large ischemic area but without infarct (ischemic penumbra) could benefit more from endovascular treatment compared to thrombolysis. In this trial, 118 patients (within 8 hours of symptom onset with occlusion of large vessels in the anterior circulation) were randomized to receive either a standard treatment or endovascular thrombectomy. The randomization procedure used stratification according to the pattern of the penumbra area: a favorable penumbral pattern (a good amount of recoverable tissue and a small infarct area) or without a penumbral pattern (large infarct area and small/absent penumbra area). The MERCI retriever was used from the beginning of the trial in 2004, and the Penumbra system was used from 2009. In this study the main outcome was also functionality measured by the Rankin scale. The trial found no evidence favouring either intervention, regardless of whether the patients had a favourable penumbra area or not. Intracranial haemorrhage rates and total mortality did not differ between the arms.

\section{More recent trials showed benefit of thrombectomy}

In 2015 five new $\mathrm{RCTs}^{16-20}$ were published showing unanimously the superiority of additional endovascular thrombectomy over standard treatment alone, in well selected patients. They all had a similar design regarding the

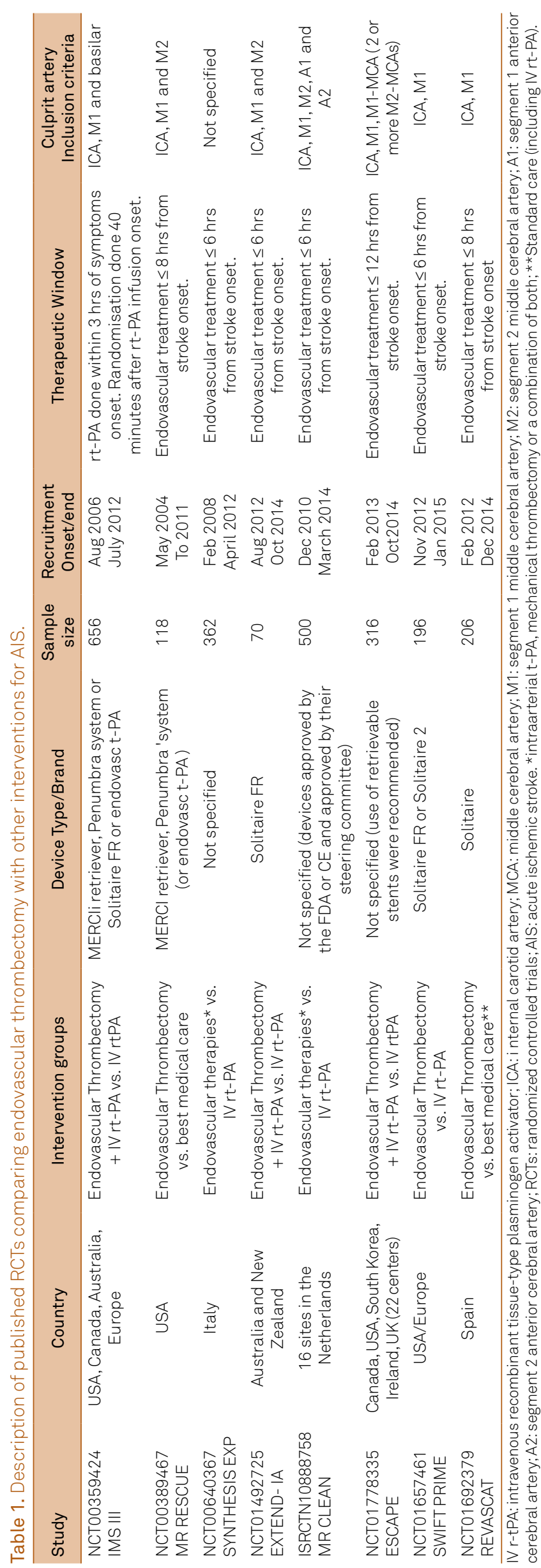


Table 2. Description of main findings of the published RCTs comparing endovascular thrombectomy with other interventions for AIS.

\begin{tabular}{|c|c|c|c|c|}
\hline Study & Country & 90 days Rankin scale & Mortality & $\begin{array}{l}\text { Symptomatic intracranial } \\
\text { hemorrhage }\end{array}$ \\
\hline $\begin{array}{l}\text { NCT00359424 } \\
\text { IMS III }\end{array}$ & $\begin{array}{l}\text { USA, Canada, } \\
\text { Australia, Europe }\end{array}$ & $\begin{array}{c}\text { Proportion with a Rankin } \\
\text { score } \leq 2 \neq 1.5 \% \text { (95\% } \mathrm{Cl}-6.1 \text { to } 9.1)\end{array}$ & $\begin{array}{l}\text { At } 90 \text { days } 19.1 \% \text { vs. } 21.6 \% \\
\qquad(p=0.52)\end{array}$ & $\begin{array}{l}\text { At hrs after rt-PA initiation } \\
6.2 \% \text { vs. } 5.9 \%(p=0.83)\end{array}$ \\
\hline $\begin{array}{l}\text { NCT00389467 } \\
\text { MR RESCUE }\end{array}$ & USA & $\begin{array}{c}\text { Mean score on the Ranking scale } \\
3.9 \text { vs. } 3.9, p=0.99\end{array}$ & At 90 days $18.7 \%$ vs. $24.1 \%$ & $5 \%$ vs. $3.7 \%$ \\
\hline $\begin{array}{l}\text { NCT00640367 } \\
\text { SYNTHESIS EXP }\end{array}$ & Italy & $\begin{array}{c}\text { Proportion with a Rankin } \\
\text { score }<2 \neq-4.4 \%(95 \% \mathrm{Cl},-14.1 \text { to } 5.2) \\
\text { OR } 0.82 ; 95 \% \mathrm{Cl}, 0.53-1.27 \mathrm{AdOR}=0.71 \\
95 \% \mathrm{Cl} 0.44-1.14\end{array}$ & At day $78 \%$ vs. $6 \% p=0.53$ & At day $76 \%$ vs. $6 \% p=0.99$ \\
\hline $\begin{array}{l}\text { NCT01492725 } \\
\text { EXTEND- IA }\end{array}$ & $\begin{array}{l}\text { Australia and } \\
\text { New Zealand }\end{array}$ & $\begin{array}{l}\text { Rankin score } 71 \% \text { vs. } 40 \% \text { Generalized } \\
\text { OR }=2.0 ; 95 \% \mathrm{Cl} 1.2-3.8\end{array}$ & $\begin{array}{l}\text { At } 90 \text { day } 9 \% \text { vs. } 20 \% \\
\text { Adj } O R=0.45(0.1-2.1)\end{array}$ & $\begin{array}{c}0 \% \text { vs. } 6 \% \text { (mean difference } \\
-6(95 \% \mathrm{Cl} ;-13 \text { to } 2)\end{array}$ \\
\hline $\begin{array}{l}\text { ISRCTN10888758 } \\
\text { MR CLEAN }\end{array}$ & $\begin{array}{l}16 \text { sites in the } \\
\text { Netherlands }\end{array}$ & $\begin{array}{c}\text { Proportion with a Rankin } \\
\text { score } \leq 2 \neq 13.5 \%(95 \% \mathrm{Cl}, 5.9 \text { to } 21.2) \\
\text { Adjusted OR of } 2.16(95 \% \mathrm{Cl}, 1.39 \text { to } 3.38)\end{array}$ & $\begin{array}{l}\text { At } 7 \text { days } 11.6 \% \text { vs. } 12.4 \% \\
\text { At } 30 \text { days } 18.9 \% \text { vs. } 18.4 \%\end{array}$ & At 90 days $7.7 \%$ vs. $6.4 \%$ \\
\hline $\begin{array}{l}\text { NCT01778335 } \\
\text { ESCAPE }\end{array}$ & $\begin{array}{l}\text { Canada, USA, } \\
\text { South Korea, } \\
\text { Ireland, UK }\end{array}$ & $\begin{array}{c}\text { Proportion with a Rankin } \\
\text { score } \leq 253 \% \text { and } 29.3 \% \text { RR } 1.4 \\
\text { (95\% 1.4-2.4) OR } 2.6(95 \% \mathrm{Cl} 1.7-3.8)\end{array}$ & $\begin{array}{l}\text { At } 30 \text { days } 10.4 \% \text { vs. } 19 \% \\
\quad \text { Dif } 8.6 \%(0.8-16.6) \\
R R=0.5(0.3-1.0) \\
\text { AdRR }=0.5(0.3-0.8)\end{array}$ & $\begin{array}{l}\text { At } 30 \text { days } 3.6 \% \text { vs. } 2.7 \% \\
\quad \text { if }=1 \%(-2.9-4.8) \\
R R=1.4(0.4-4.7) \\
\text { AdRR }=1.2(0.3-4.6)\end{array}$ \\
\hline $\begin{array}{l}\text { NCT01657461 } \\
\text { SWIFT PRIME }\end{array}$ & USA/Europe & $\begin{array}{c}\text { Proportion with a Rankin } \\
\text { score } \leq 260 \% \text { and } 35 \% \\
\text { RR }=1.70(95 \% \mathrm{Cl} 1.23-2.33)\end{array}$ & $\begin{array}{l}\text { At } 90 \text { day } 9 \% \text { vs. } 12 \% \\
p=0.50\end{array}$ & $\begin{array}{c}\text { At } 27 \text { hrs } 0 \text { vs. } 3 \% \\
p=0.12\end{array}$ \\
\hline REVASCAT & Spain & $\begin{array}{l}\text { Proportion with a Rankin score } \leq 243.7 \% \\
\text { and } 28.2 \% \mathrm{OR}=2.1(95 \% \mathrm{Cl} 1.2-4.0)\end{array}$ & $\begin{array}{l}\text { At } 90 \text { day } 18 \% \text { vs. } 15.5 \% \\
\qquad p=0.60\end{array}$ & $\begin{array}{l}\text { At } 90 \text { days } 1.9 \% \text { vs. } 1.9 \% \\
\qquad p=1.00\end{array}$ \\
\hline
\end{tabular}

RCTs: randomized controlled trials; AIS: acute ischemic stroke; OR: Odds Ratio; RR: Relative Risk.

groups compared. Most compared endovascular thrombectomy plus IV rt-PA with IV rt-PA alone and used more recent devices. They also had more similar inclusion criteria: all required proximal intracranial occlusion in the anterior circulation and most used 6 hours from symptoms onset as their therapeutic window for the endovascular treatment.

\section{EXTEND-IA trial}

Campbell et al. ${ }^{17}$ (EXTEND-IA) conducted the smallest of these five trials, with only 70 patients, who were eligible to receive IV rt-PA within 4.5 hours of symptom onset and with an internal carotid or middle cerebral artery occlusion. They were randomized to receive IV rt-PA only or to additionally receive endovascular thrombectomy with the Solitaire FR stent retriever. They had two primary outcomes: reperfusion at 24 hours (which was higher in the endovascular treatment group: $100 \%$ vs. $37 \%, \mathrm{p}<0.001$ ) and early neurological improvement (NIHSS $>$ 8-point reduction in 3 days, which was higher in the endovascular group: $80 \%$ vs. $37 \%, p=0.002$ ). They also assessed functional independence at 30 days using the Rankin scale ${ }^{15}$, showing again superiority of the endovascular thrombectomy group ( $71 \%$ vs. $40 \%, p=0.001)$. There was a no statistically significant difference in the mortality rates at 90 days ( $9 \%$ vs. $20 \%$; adj OR $=0.45$ (95\%CI; 0.1-2.1)) and symptomatic intracranial haemorrhage ( $6 \%$ vs. 0 , mean difference $=-6(95 \% \mathrm{CI},-13$ to 2$)$.

\section{MR CLEAN trial}

The Multicenter Randomized Clinical Trial of Endovascular Treatment in the Netherlands (MR CLEAN) ${ }^{16}$ was a much larger trial with 500 patients from 16 different centres in the Netherlands. They randomly allocated patients with proven anterior circulation large vessel occlusion to receive an endovascular treatment plus usual care (thrombolysis, mechanical thrombectomy or both) or usual care only. Usual care could or could not include the use of intravenous alteplase, however $89 \%$ of the total sample were treated with intravenous alteplase before randomization. The authors have not specified the devices used (only that they were devices approved by the FDA and CE and by their steering committee). The primary outcome defined in this study was a measure of functional independence 90 days after the intervention using the Rankin scale, which showed an absolute mean difference of $13.5 \%$ (95\%CI, 5.9-21.2) in the rate of functional independence between the two arms. There was no difference in mortality rates at 30 days $(18.9 \%$ vs. $18.4 \%)$ and rates of symptomatic intra-cerebral haemorrhage ( $7.7 \%$ vs. $6.4 \%)$.

\section{ESCAPE trial}

Goyal et al. $(E S C A P E)^{18}$ used data from 22 centres from the USA, Canada, South Korea, Ireland and the UK, with 316 patients randomized to receive standard care or standard care plus endovascular treatment with available thrombectomy devices. Although the authors have not specified the devices used they state that the use of stent retrievers were recommended. Unlike the other RCTs, in the ESCAPE trial patients were included up to $12 \mathrm{hrs}$ after symptom onset. The primary outcome defined in this study was also functional independence at 30 days using the Rankin scale, which showed a much higher proportion of patients with functional independence in the intervention group (53\% vs. $29.3 \%$, 


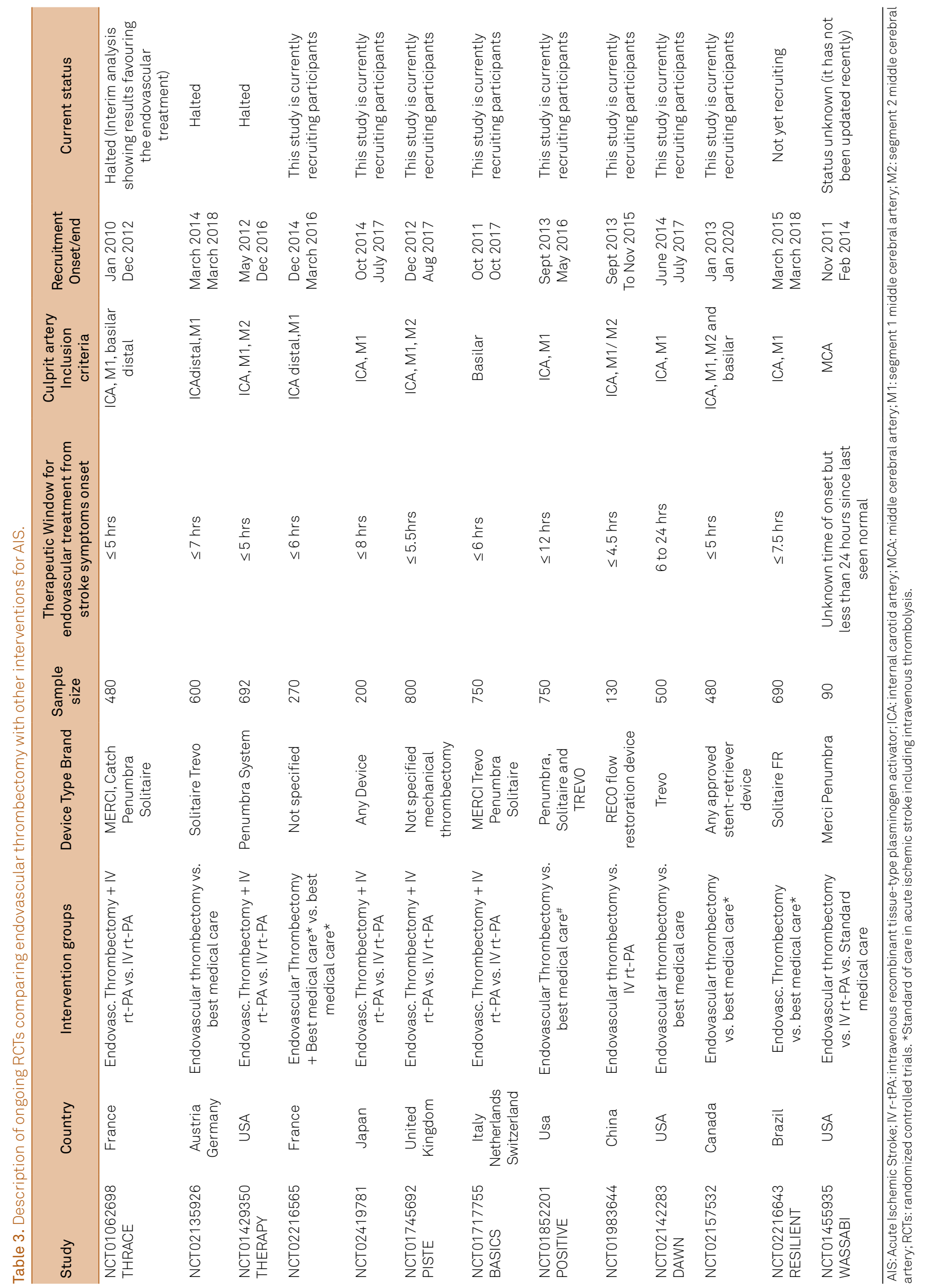


$\mathrm{p}<0.001$ ). In this trial endovascular thrombectomy was associated with reduced mortality (absolute difference of 8.6\% (95\%CI, 0.8-16.6) and there was no statistically significant difference of rates of symptomatic intra-cerebral haemorrhage between the two groups (absolute difference of $1 \%$ (95\%CI, -2.9 to 4.8 ). However, in this study there was a much higher rate of a new ischemic stroke in a different vascular territory in the intervention group than in the control group (5.6\% vs. $0.4 \%, \mathrm{p}<0.001)$.

\section{SWIFT PRIME trial}

The SWIFT PRIME ${ }^{20}$ was terminated early because of efficacy. From December 2012 to November 2014, 196 patients who received IV rt-PA from 39 centres in the USA and Europe were randomized to continue with IV rt-PA alone or to additionally receive endovascular treatment (mechanical thrombectomy). The endovascular thrombectomy was performed using the Solitaire FR (flow restoration) or Solitaire 2 device. Functional independence at 90 days using the Rankin scale was higher in the intervention group (60\% vs. $35 \%$, $\mathrm{p}<0.001$ ) with an absolute difference of $25 \%$ which was much higher than the 12 percentage point boundary that was pre-specified for early termination. Mortality at 90 days and symptomatic intra-cerebral haemorrhage at 27 days were similar in both groups ( $9 \%$ vs. $12 \%, p=0.50$ and 0 vs. $3 \%$, $\mathrm{p}=0.12$ respectively).

\section{REVASCAT trial}

The REVASCAT trial ${ }^{19}$ had planned to enrol 690 subjects in the trial, but was halted early because of loss of equipoise after positive results from other RCTs were published. Between February 2012 and December 2014, 206 eligible patients were enrolled (who were either ineligible for IV rt-PA or had no recanalization after 30 minutes of the start of IV rt-PA). They were randomized to receive or not receive the endovascular treatment, which was performed using the Solitaire stent retriever. Their primary outcome was the score on the modified Rankin scale which showed an OR of improvement in its distribution of 1.7 (95\%CI 1.05-2.8) favouring thrombectomy. It also showed that functional independence was higher in the thrombectomy arm, $43.7 \%$ of patients having a score between 0 and 2 against $28.3 \%$ in the control group (adj OR $=2.1$ (95\% CI 1.1 to 4.0). There was no difference between the groups regarding safety variables of mortality and symptomatic intra-cerebral haemorrhage at 90 days ( $18.4 \%$ vs. $15.5 \%$, $\mathrm{p}=0.60$ and $1.9 \%$ vs. $1.9 \%, \mathrm{p}=1.0$ respectively).

\section{Ongoing Randomized controlled trials}

We identified 13 eligible ongoing RCTs whose details are described in Table 3. One of them (NCT1455935) for which data collection was predicted to finish by February 2014 has an unknown status (it has not been updated recently). Three of them have been halted: NCT01429350, NCT02135926 and NCT01062698. The latter (NCT01062698) called THRACE trial was halted in March 2015 on the advice of their Data Safety and Monitoring Board after enrolling 412 of 480 planned subjects. A positive treatment effect for the endovascular treatment had been announced based on the first 395 subjects $^{21}$. From the remaining 9 trials, one has not started recruitment yet (NCT02216643). This trial to be conducted in Brazil, is going to use the solitaire FR with a planned sample of 690 patients recruited from 2015 to March 2018. The 8 remaining registered ongoing trials which are still recruiting started recruitment between October 2011 and December 2014 and are planned to end between November 2015 and January 2020. Three of them are being conducted in Europe (NCT02216565, NCT01745692, NCT01717755), one in the USA (NCT01852201), one in the USA and Europe (NCT02142283), one in Japan (NCT02419781), one in China (NCT01983644) and one in Canada (NCT02157532). These trials have similar group arms, the most common being the comparison between endovascular thrombectomy plus IV rt-PA with IV rt-PA alone. There are important variations in the inclusion criteria, therapeutic windows and devices used.

\section{DISCUSSION}

The thrombectomy devices assessed in this review were approved by the FDA without any requirement for strong evidence of clinical efficacy. The devices were approved in the USA after few non controlled clinical trials suggested that they could be effective in the recanalization of the occlusion of large vessels ${ }^{22,23}$. This early approval encouraged the spread of their use despite the lack of clear evidence of their efficacy at the time.

\section{No superiority of thrombectomy}

The first three published RCTs identified in this review showed no superiority of the endovascular treatment compared to intravenous thrombolysis with the safety profile being similar between the intervention groups. While thrombectomy did not show superior efficacy in the SYNTHESIS and MR RESCUE studies; the IMS III was prematurely interrupted due to futility, i.e., showed evidence, in earlier stages of the trial, that final results would not favour the new technology.

However, a sub-analysis of the IMS III ${ }^{12}$, suggested the possibility of benefit of thrombectomy for a specific group of patients, the benefit being observed if this technology was used within 3:30 hrs after the onset of symptoms. In addition, patients were included even if the occluded vessel was a small distal one, when any benefit from mechanical intervention is unlikely.

\section{Superiority of thrombectomy}

The five recently published trials have shown a superiority of endovascular treatment plus IV rt-PA over IV rt-PA alone within a wider therapeutic window. Three of them ${ }^{16,17,24}$ 
conducted the endovascular thrombectomy within 6 hours of symptom onset, one within 8 hours ${ }^{19}$, while Goyal et al. ${ }^{18}$ conducted it within 12 hours of symptom onset.

\section{The devices for thrombectomy}

It is important to highlight that one of the main limitations of the three initial RCTs was the fact that they used first generation devices. Clinical trials comparing different types of devices have shown that the stent retriever, developed more recently, could be more effective than the first generation devices in terms of recanalization rates and the time taken to achieve $i^{25,26}$.This might be reflected in the results of the five recent positive trials. Campbell at $\mathrm{al}^{17}$ and Saver at $\mathrm{al}^{24}$ used the most recent technology of stent retriever (Solitaire FR and Solitaire 2) while Berkhemer at al. ${ }^{16}$ did not specify the devices used, but by the end of the trial $82 \%$ of the patients randomized to endovascular treatment had the procedure with stent retriever devices ${ }^{16,21}$; and Goyal et $\mathrm{al}^{18}$ conducted a trial that allowed the use of any available thrombectomy device, but recommended the use of retrievable stents and in practice newer generation devices were used ${ }^{18,21}$.

\section{When to use Thrombectomy?}

The recent positive results regarding endovascular thrombectomy are believed to be greatly influenced by the inclusion criteria ${ }^{27}$, that favour cases of stroke with proved proximal vessel occlusion, which are associated with more voluminous thrombus and are less prone to respond to pharmacological intervention.

In summary, patient inclusion criteria and the type of device used, as well as the timing of endovascular treatment were important aspects that might have influenced the positive results of these recent trials.

\section{Implications for clinical practice and future reviews}

The translation of these positive trials to the actual widespread use of these new methods of treatment with similar positive results will be a challenging task. Stroke systems will need to adapt to provide patients with access to acute stroke therapies such as IV rtPA and thrombectomy in a timely, equitable, and safe fashion ${ }^{28}$. Early treatment requires increased patient awareness, faster pre-hospital assistance and transfers, effective in-hospital patient pathways, and readiness for acute stroke interventions. Such hospitals should guarantee prompt 24/7 neurological and brain imaging services, preferably with stroke units for better patient care. The decision to use thrombectomy should be made by a multidisciplinary team comprising at least a stroke physician and a trained and experienced neurointerventionist ${ }^{29}$. Neurointervention usually requires at least 2 years of training in addition to completing radiology, neurosurgery, or neurology training, and intracranial catheter manipulation experience ${ }^{27}$.

\section{Trained specialists and telemedicine}

One way to access well trained specialists is to use telemedicine. Telestroke networks are important tools for diagnostic and treatment support of acute stroke patients for less well-resourced hospitals and also for the referral of selected patients to more qualified institutions. Telestroke has been proved to be a safe, efficient and cost-effective strategy for stroke care ${ }^{30}$.

\section{Possible limitations}

It is important to remember that endovascular thrombectomy requires general anaesthetic, although some recent studies have shown that it is preferable to carry out the procedure using conscious sedation ${ }^{31,32}$. Despite the potential efficacy of endovascular treatment, in particular using the stent retriever technology that results in higher rates of optimal perfusion, its higher cost compared to other technologies ${ }^{33}$ adds to the challenge of the use of this new technology and further studies are needed to prove its cost-effectiveness.

\section{FINAL REMARKS}

These new positive findings favoring the association of endovascular thrombectomy combined with the current standard treatment of stroke with proximal vessel occlusion should be viewed as a promising step toward the development of treatments that can benefit as many patients as possible.

It has to be stressed that the indication of intravenous thrombolysis does not prevent the endovascular approach but instead might be a condition for its success.

Several RCTs are being conducted at the moment, which are predicted to finish between 2016 and 2020 and their results should be monitored as they will build on the current evidence and will better define the role of the thrombectomy for acute ischemic stroke.

\section{References}

1. Lavados PM, Hennis AJ, Fernandes JG, Medina MT, Legetic B, Hoppe A et al. Stroke epidemiology, prevention, and management strategies at a regional level: Latin America and the Caribbean. Lancet Neurol. 2007;6(4):362-72. doi:10.1016/S1474-4422(07)70003-0

2. World Health Organization. The world health report 2000: health systems: improving performance. Geneva: World Health Organization, 2000.
3. Mansur AP, Souza MFM, Favarato D, Avakian SD, César LAM, Aldrigui $\mathrm{JM}$ et al. Stroke and ischemic heart disease mortality trends in Brazil from 1979 to 1996. Neuroepidemiology. 2003;22(3):179-83. doi:10.1159/000069893

4. Strong K, Mathers C, Bonita R. Preventing stroke: saving lives around the world. Lancet Neurol. 2007;6(2):182-7. doi:10.1016/S1474-4422(07)70031-5 
5. Ferri CP, Schoenborn C, Kalra L, Acosta D, Guerra M, Huang Y et al. Prevalence of stroke and related burden among older people living in Latin America, India and China. Journal J Neurol Neurosurg Psychiatry. 2011;82(10):1074-82. doi:10.1136/jnnp.2010.234153

6. World Health Organization, Health Statistics and Information Systems. The global burden of cerebrovascular disease. Geneva: World Health Organization [cited Aug 2015]. Available from: http://www.who.int/healthinfo/statistics/bod_ cerebrovasculardiseasestroke.pdf

7. Copstein L, Fernandes JG, Bastos GA. Prevalence and risk factors for stroke in a population of Southern Brazil. Arq Neuropsiquiatr. 2013;71(5):294-300. doi:10.1590/0004-282X20130024

8. Mozaffarian D, Benjamin EJ, Go AS, Arnett DK, Blaha MJ, Cushman M et al. Heart disease and stroke statistics: 2015 update: a report from the American Heart Association. Circulation. 2015;131(4):e29-322. doi:10.1161/CIR.0000000000000152

9. Jauch EC, Saver JL, Adams HP Jr, Bruno A, Connors JJ, Demaerschalk BM et al. Guidelines for the early management of patients with acute ischemic stroke: a guideline for healthcare professionals from the American Heart Association/American Stroke Association. Stroke. 2013;44(3):870-947.

10. Rios la Rosa F, Khoury J, Kissela BM, Flaherty ML, Alwell K, Moomaw CJ et al. Eligibility for Intravenous Recombinant Tissue-Type Plasminogen Activator Within a Population: The Effect of the European Cooperative Acute Stroke Study (ECASS) III Trial. Stroke. 2012;43(6):1591-5. doi:10.1161/STROKEAHA.111.645986

11. Riedel $\mathrm{CH}$, Zimmermann $P$, Jensen-Kondering $U$, Stingele $R$, Deuschl G, Jansen O. The importance of size: successful recanalization by intravenous thrombolysis in acute anterior stroke depends on thrombus length. Stroke. 2011;42(6):1775-7. doi:10.1161/STROKEAHA.110.609693

12. Broderick JP, Palesch YY, Demchuk AM, Yeatts SD, Khatri P, Hill $\mathrm{MD}$ et al. Endovascular therapy after intravenous t-PA versus t-PA alone for stroke. N Engl J Med. 2013;368(10):893-903. doi:10.1056/NEJMoa1214300

13. Ciccone A, Valvassori L, Nichelatti M, Sgoifo A, Ponzio M, Sterzi R et al. Endovascular treatment for acute ischemic stroke. N Engl J Med. 2013;368(10):904-13. doi:10.1056/NEJMoa1213701

14. Kidwell CS, Jahan R, Saver JL. Endovascular treatment for acute ischemic stroke. N Engl J Med. 2013;368(25):2434-5. doi:10.1056/NEJMoa1213701

15. Swieten JC, Koudstaal PJ, Visser MC, Schouten HJ, Gijn J. Interobserver agreement for the assessment of handicap in stroke patients. Stroke. 1988;19(5):604-7. doi:10.1161/01.STR.19.5.604

16. Berkhemer OA, Fransen PS, Beumer D, Berg LA, Lingsma HF, Yoo AJ et al. A randomized trial of intraarterial treatment for acute ischemic stroke. N Engl J Med. 2015;372(1):11-20. doi:10.1056/NEJMoa1411587

17. Campbell BC, Mitchell PJ, Kleinig TJ, Dewey HM, Churilov $L$, Yassi $N$ et al. Endovascular therapy for ischemic stroke with perfusion-imaging selection. The N Engl J Med. 2015;372(11):1009-18. doi:10.1056/NEJMoa1414792

18. Goyal M, Demchuk AM, Menon BK, Eesa M, Rempel JL, Thornton $J$ et al. Randomized assessment of rapid endovascular treatment of ischemic stroke. N Engl J Med. 2015;372(11):1019-30. doi:10.1056/NEJMoa1414905

19. Jovin TG, Chamorro A, Cobo E, Miquel MA, Molina CA, Rovira A et al. Thrombectomy within 8 hours after symptom onset in ischemic stroke. N Engl J Med. 2015;372(24):2296-306. doi:10.1056/NEJMoa1503780
20. Saver JL, Goyal M, Bonafe A, Diener HC, Levy EI, Pereira $\mathrm{VM}$ et al. Stent-retriever thrombectomy after intravenous t-PA vs. t-PA alone in stroke. N Engl J Med. 2015;372(24):2285-95. doi:10.1056/NEJMoa1415061

21. Khatri P, Hacke W, Fiehler J, et al. State of acute endovascular therapy: report from the 12th thrombolysis, thrombectomy, and acute stroke therapy conference. Stroke. 2015;46(6):1727-34. doi:10.1161/STROKEAHA.115.008782

22. Smith WS, Sung G, Starkman S, Saver JL, Kidwell CS, Gobin YP et al. Safety and efficacy of mechanical embolectomy in acute ischemic stroke: results of the MERCI trial. Stroke. 2005;36(7):1432-8. doi:10.1161/01.STR.0000171066.25248.1d

23. Penumbra Pivotal Stroke Trial Investigators. The penumbra pivotal stroke trial: safety and effectiveness of a new generation of mechanical devices for clot removal in intracranial large vessel occlusive disease. Stroke. 2009;40(8):2761-8. doi:10.1161/STROKEAHA.108.544957

24. Saver JL, Goyal M, Bonafe A, Diener HC, Levy El, Pereira $\mathrm{VM}$ et al. Stent-retriever thrombectomy after intravenous t-PA vs. t-PA alone in stroke. N Engl J Med. 2015;372(24):2285-95. doi:10.1056/NEJMoa1415061

25. Saver JL, Jahan R, Levy El, Jovin TG, Baxter B, Nogueira RG et al. Solitaire flow restoration device versus the Merci Retriever in patients with acute ischaemic stroke (SWIFT): a randomised, parallel-group, non-inferiority trial. Lancet. 2012;380(9849):1241-9. doi:10.1016/S0140-6736(12)61384-1

26. Nogueira RG, Lutsep HL, Gupta R, Jovin TG, Albers GW, Walker GA et al. Trevo versus Merci retrievers for thrombectomy revascularisation of large vessel occlusions in acute ischaemic stroke (TREVO 2): a randomised trial. Lancet. 2012;380(9849):1231-40. doi:10.1016/S0140-6736(12)61299-9

27. Campbell BC, Donnan GA, Lees KR, Hacke W, Khatri P, Hill MD et al. Endovascular stent thrombectomy: the new standard of care for large vessel ischaemic stroke. Lancet Neurol. 2015;14(8):846-54. doi:10.1016/S1474-4422(15)00140-4

28. Smith EE, Schwamm LH. Endovascular clot retrieval therapy: implications for the organization of stroke systems of care in north america. Stroke. 2015;46(6):1462-7. doi:10.1161/STROKEAHA.115.008385

29. Tatlisumak T. Implication of the recent positive endovascular intervention trials for organizing acute stroke care: European perspective. Stroke. 2015;46(6):1468-73. doi:10.1161/STROKEAHA.115.008386

30. Hunter RM, Davie C, Rudd A, Thompson A, Walker H, Thomson $\mathrm{N}$ et al. Impact on clinical and cost outcomes of a centralized approach to acute stroke care in London: a comparative effectiveness before and after model. PloS one. 2013;8(8):e70420. doi:10.1371/journal.pone.0070420

31. John N, Mitchell P, Dowling R, Yan B. Is general anaesthesia preferable to conscious sedation in the treatment of acute ischaemic stroke with intra-arterial mechanical thrombectomy? A review of the literature. Neuroradiology. 2013;55(1):93-100. doi:10.1007/s00234-012-1084-y

32. Takahashi C, Liang CW, Liebeskind DS, Hinman JD. To tube or not to tube? The role of intubation during stroke thrombectomy. Front Neurol. 2014;5:170. doi:10.3389/fneur.2014.00170

33. Kass-Hout T, Kass-Hout O, Sun CH, Kass-Hout T, Belagaje $\mathrm{SR}$, Anderson AM et al. Periprocedural cost-effectiveness analysis of mechanical thrombectomy for acute ischemic stroke in the stent retriever era. Interv Neurol. 2015;3(2):107-13. doi:10.1159/000371729 